Bangladesh J. Bot. 48(4): 943-949, 2019 (December)

\title{
ANTIMICROBIAL POTENTIAL OF DIFFERENT SOLVENT EXTRACTS OF MORCHELLA ESCULENTA (L.) PERS.
}

\author{
Wajid Khan*, Zainab Bibi, Muhammad NaZir Uddin, Huma Gul \\ AND HaYat KHAN ${ }^{1}$ \\ Center for Biotechnology and Microbiology, University of Swat, Pakistan
}

Keywords: Extracts, Disc diffusion, Antimicrobial activity, Extraction solvent

\begin{abstract}
The antimicrobial activity of different extracts (methanolic, ethyl acetate, hot and cold water extracts) of Morchella esculenta against bacterial strains including Agrobacterium tumefaciens, Bacillus atrophaeus, Bacillus subtilis, Citrobactor freundii, Escherichia coli, Klebsiella pneumoniae, Salmonella typhi, Staphyllococcus aureus, Staphyllococcus epidermidis, Pseudomonas aeruginosa and Xanthomonas oryzae and some fungal strains such as Trychophyton rubrum, Rhizopus stolonifer,Trichoderma citrinoviride, Aspergillus fumigatus and Alternaria alternata was evaluated. Disc diffusion assay was used for antibacterial activity and well diffusion method was applied for measuring the antifungal activities of different extracts. Hot water extract was found more effective against bacterial strains and produced maximum zone of inhibition of $90 \%$ against Bacillus atrophaeus at $3 \mathrm{mg} / \mathrm{disc}$, while cold water extract showed strong activity against the majority of selected fungal strains; Trichophyton rubrum, Trichoderma citrinoviride and Alternaria alternata. Ethyl acetate extract of $M$. esculenta revealed least antimicrobial activities against the tested microbes.
\end{abstract}

\section{Introduction}

Scarcity of new antimicrobial and increasing antibiotic resistance are major risks to global health care (Walsh and Toleman 2012). Development of antimicrobial resistance in both humans and animals is due to number of factors which include excessive and inappropriate use of antibiotics, high application of these agents as growth enhancers in animal feed (Lowy 2003, Andersson and Hughes 2011). In this situation, the development of novel and alternative classes of drugs with least side effect to treat microbial infection is urgently needed (Srivastava et al. 2013).

M. esculenta is also one of the medicinal mushroom having high medicinal value, and commercially available in Pansara markets. In some research reports, M.esculenta has shown antioxidant, antiallergenic, antitumor, anti-inflammatory, antiseptic, neuroprotective and antimicrobial properties (Baati et al. 2011, Mahmood et al. 2011, Halliwell 2012, Heleno et al. 2013). So far, data regarding the effect of extraction solvents on antimicrobial potential of M.esculenta have not been reported. Therefore, in the present study antibacterial potential of different solvent extracts of M.esculenta was investigated.

\section{Material and Methods}

M. esculenta was collected from district Swat and taxonomically identified by Assistant Prof. Dr. Zahid Khan, Department of Botany, University of Swat, Khyber-Pakhtunkhwa (KPK) Pakistan.

*Author for correspondence: <wajidbiotech33@gmail.com>. ${ }^{1}$ Department of Microbiology, University of Swabi. 
Analytical grade solvents were used in the extraction (Merck \& Co., Inc., Kenilworth, NJ, USA). Nutrient agar and nutrient broth were purchased from Musaji Adam \& Sons. Ciprofloxacin and Terbinafine were provided by Meditech Pharmaceuticals Peshawar, Pakistan. Whatman filter paper was used for filtration and Rotary evaporator (Rotavapor R-R 210/R215; BUCHIL Labortechnik AG) for drying solutions.

Three hundred gram of dried crushed mushrooms (M. esculenta) was mixed with one liter of analytical grade methanol in extraction flask. The flask was shaken twice a day for four consecutive days. At the end of the shaking period, the solution was filtered through Whatman filter paper. The filtered solution contained methanol soluble compounds. Methanol was separated from solution through rotary evaporator at $35^{\circ} \mathrm{C}$, leaving paste which was then dried in China dish. The dried extract known as crude methanol extract was weighted and stored in clean and sterilized vials. The solid residues in the extraction flask was treated with other solvents (n hexane, ethyl acetate, Hot and cold water) using the same methodology of extraction.

Nutrient agar and nutrient broth were prepared according to standard procedure for antimicrobial bioassay (Khan et al. 2017). For fungal bioassay, potato dextrose medium was prepared from $300 \mathrm{~g}$ of potatoes extract, $20 \mathrm{~g}$ of dextrose, $20 \mathrm{~g}$ of agar and 1 litre of water. Other accessories and media containing bottle were autoclaved at $15 \mathrm{psi}$ for $15 \mathrm{~min}$ at $121^{\circ} \mathrm{C}$. Media were poured into Petri plates under sterile condition.

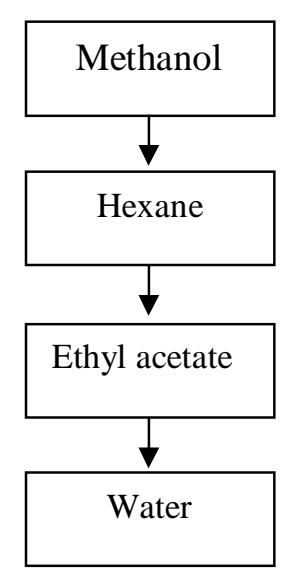

Fig. 1. Solvents used for extraction on the ascending order of polarity.

Well diffusion method was used for antifungal bioassay while disc diffusion method was performed for antibacterial bioassay. Bacterial species used in the present study were Agrobacterium tumefaciens, Bacillus atrophaeus, Bacillus subtilis, Citrobactor freundii, Escherichia coli, Klebsiella pneumoniae, Salmonella typhi, Staphyllococcus aureus, Staphyllococcus epidermidis, Pseudomonas aeruginosa and Xanthomonas oryzae. Among the fungal species were Trichophyton rubrum, Trichoderma citrinoviride and Alternaria alternata. Bacterial strains were cultured and standardized on nutrient agar medium and nutrient agar broth respectively, while potato dextrose agar and broth were used for culturing and standardization of fungal strains (Khan et al. 2016). 


\section{Results and Discussion}

Selection of the suitable solvents for the optimum anti-microbial activity and antioxidant activity of the extract is one of the challenging tasks due to the difference in solubility of bioactive compounds in various solvent (Khan et al. 2018). Thus preliminary screening is an essential to select the best solvent that finalizes the optimum bio activity of extract (Khan et al. 2017). The present study was conducted to find out the effect of different extraction solvents on antibacterial and antifungal activities of $M$. esculenta against selected bacterial and fungal strains. Four different solvent extracts were prepared and tested for antibacterial and antifungal activity. During the study M. esculenta was found to be more effective against bacteria as compared to fungi. The results showed that hot water extract was more effective against $B$. atrophaeus, $C$. freundii, $P$. aeruginosa, S. aureus and E. coli, Xanthomonas oryzae, S. aureus, E. coli as compared to other tested samples (Figs 1B, 2A, 2B) while the same extract was found to be ineffective against $A$. tumefaciens and $S$. typhi (Figs 1A, 3). Effective inhibitory activity against $E$. coli and $S$. aureus was found in ethanol extract (Badsha et al. 2012, Kalyoncu et al. 2010). The effectiveness of hot water might be due to the activation of strong bioactive compounds at high temperature or it might be possible that high temperature degrade the bio active compounds and the residuals of the degraded compounds might have strong antimicrobial efficacy as compared to the parental compounds. Cold water extract was effective against S. typi, S. epidermidis and K. penumoniae (Figs 3A, 5B, 6A). Similar findings were also reported in ethanol extract by Badsha et al. (2012). However, the cold water extract did not produce ZI against $C$. freunjii and $A$.tumefaciens.
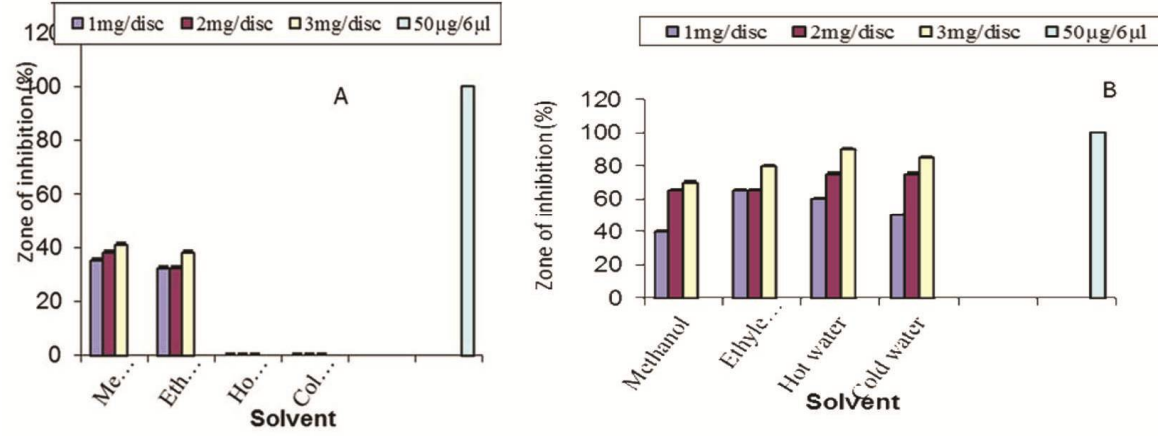

Fig. 1. Antibacterial efficacy of different solvent extracts of M. esculenta extract against Agrobacterium (A) and B. autropus (B) (Bar represents mean $\pm \mathrm{Sd}$ ).
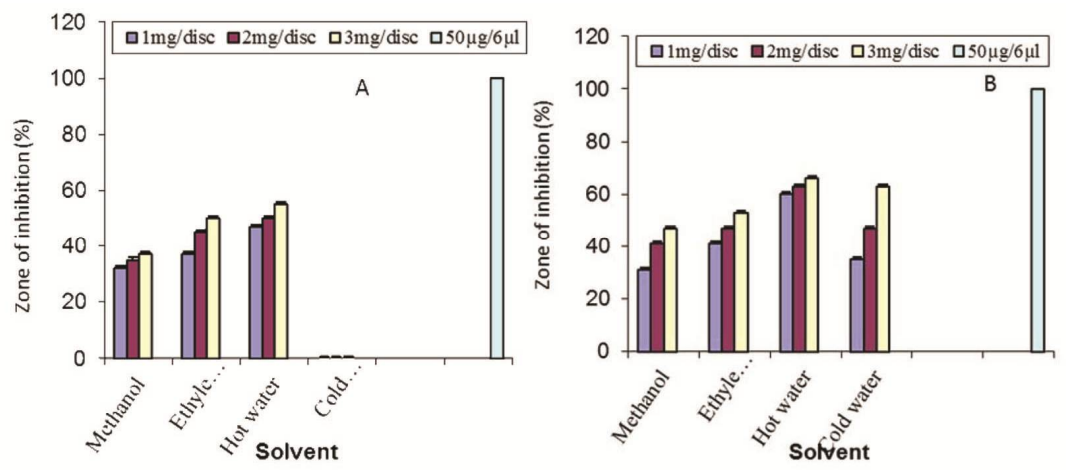

Fig. 2. Antibacterial activities of different solvent extracts of $M$. esculenta extract against Citrobacter freundii (A) and P. aerginosa (B), (Bar represents mean $\pm \mathrm{Sd})$. 

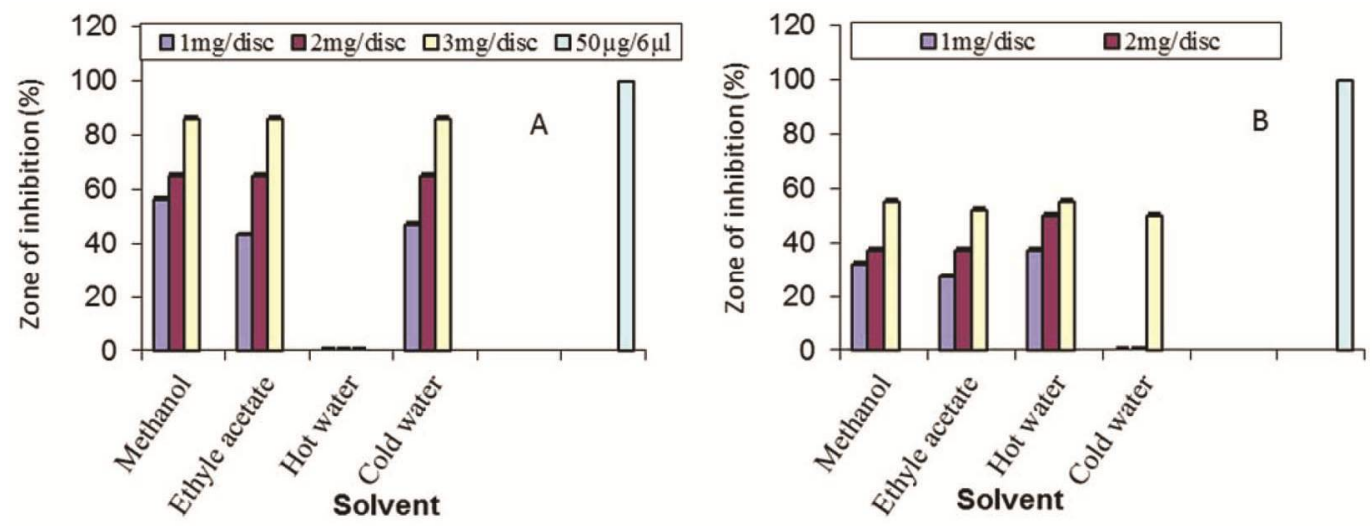

Fig. 3. Antibacterial activities of different solvent extracts of M. esculenta extract against S. typhi (A) and $X$. oryzae $(\mathrm{B})$, (Bar represents mean $\pm \mathrm{Sd})$.
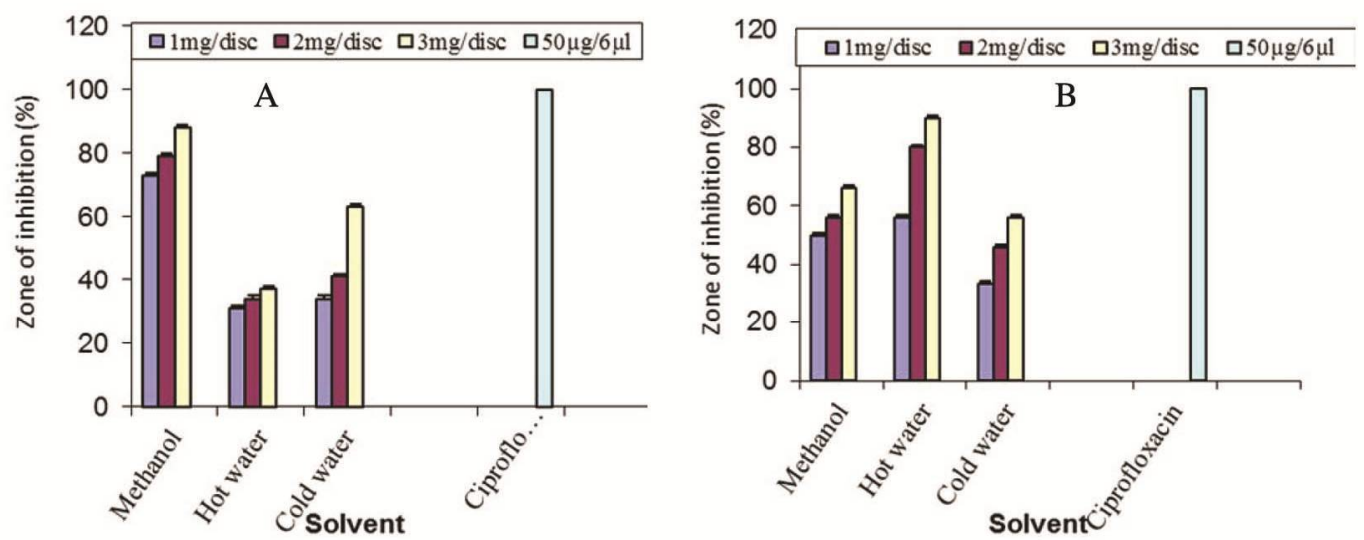

Fig. 4. Antibacterial activities of different solvent extracts of M. esculenta extract against B. subtilis (A) and S. aureus (B), Bar represents mean $\pm \mathrm{Sd}$ ).
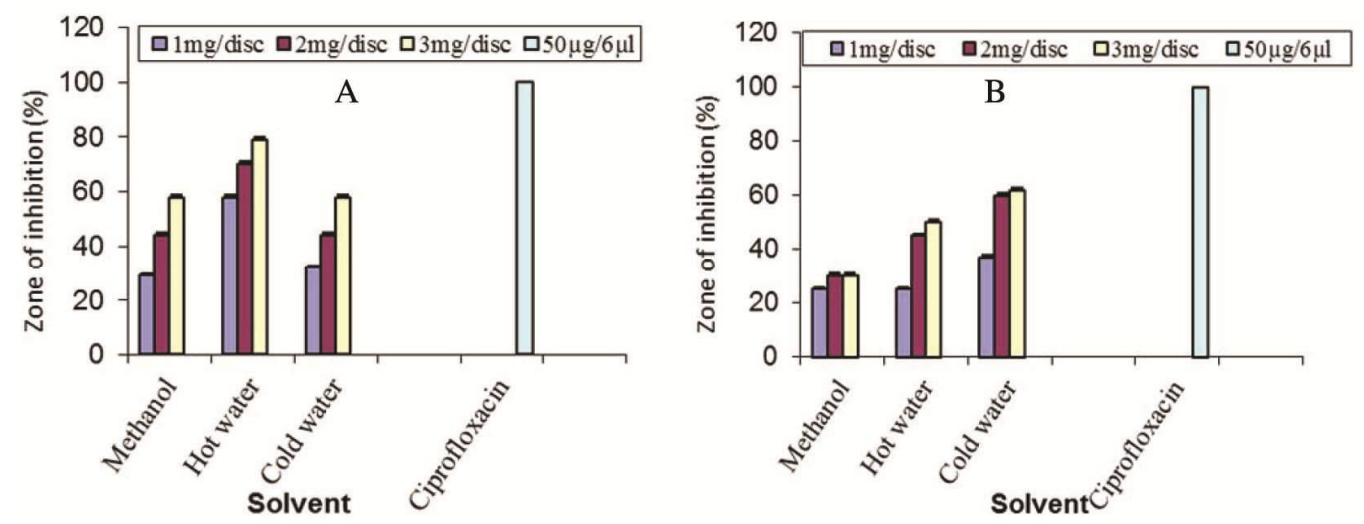

Fig. 5. Antibacterial activities of different solvent extracts of $M$. esculenta extract against $E$. coli. (A) and S. epidermidis (B), (Bar represents mean $\pm \mathrm{Sd}$ ). 

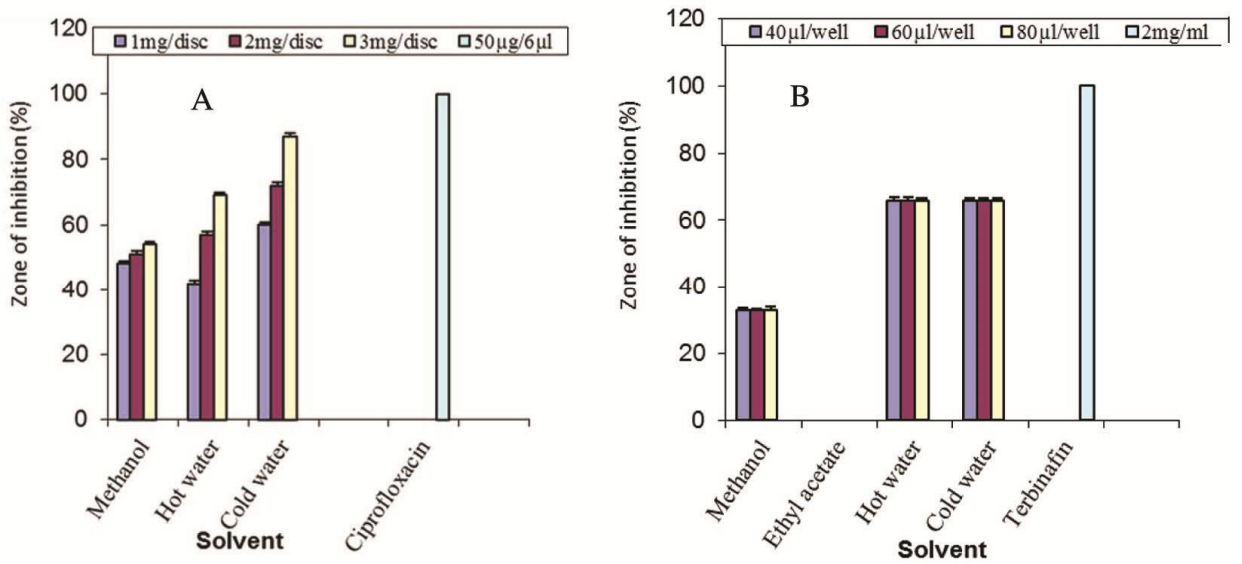

Fig. 6. Antibacterial activities of different solvent extracts of M. esculenta extract against K. pneumonia (A) and T. rubrum (B). (Bar represents $\pm \mathrm{Sd}$ ).
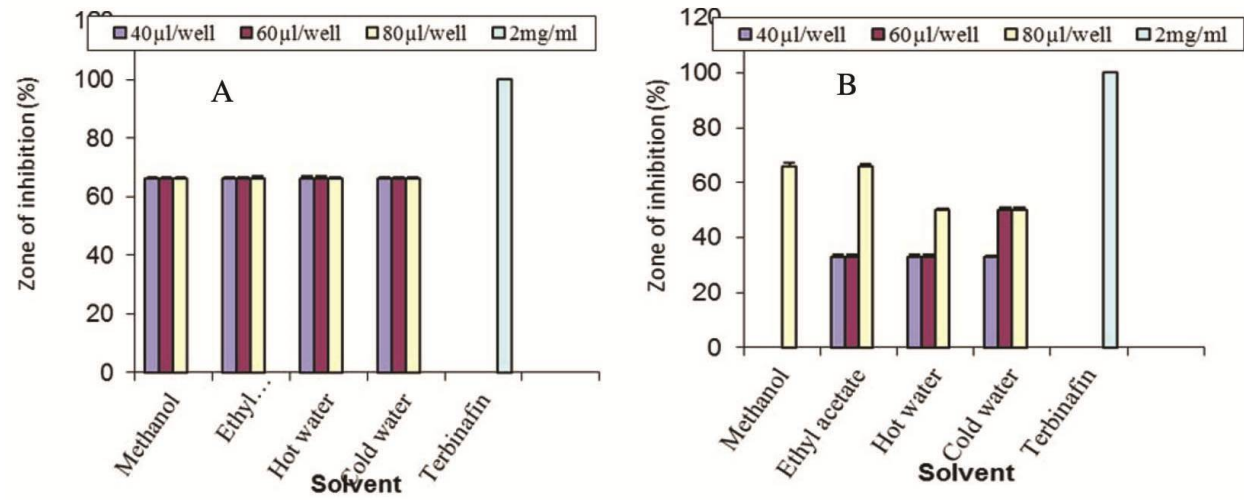

Fig. 7. Antifungal efficacy of the different solvents extracts of $M$. esculenta against $R$. stolonifer (A) and against $T$. citrinoviride (Bar represents $\pm \mathrm{Sd}$ ).
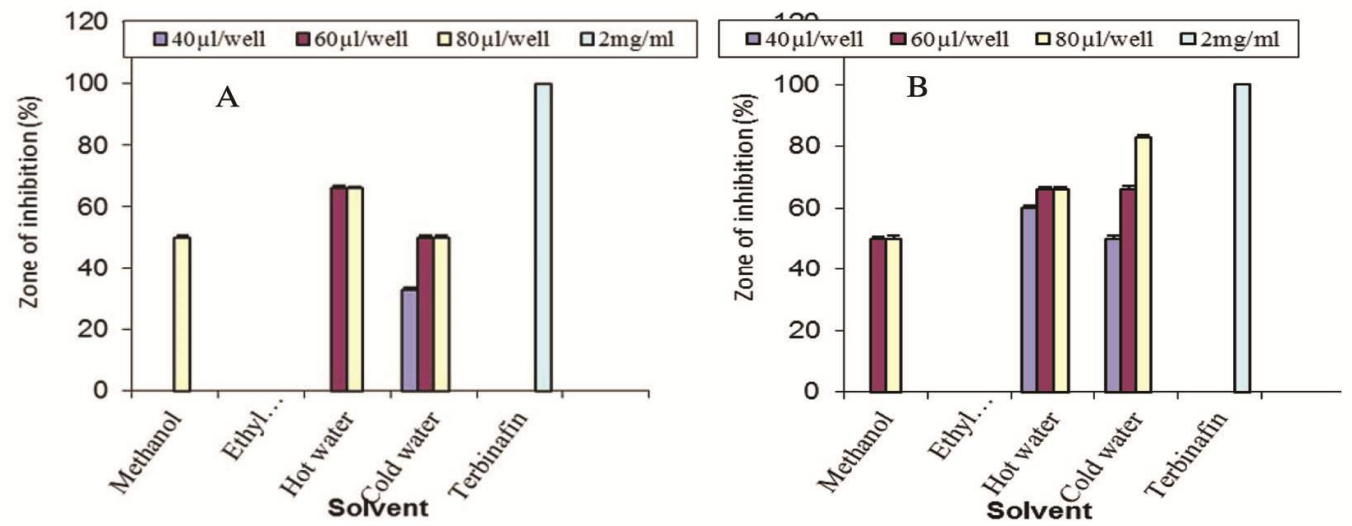

Fig. 8. Antifungal efficacy of the different solvents extracts of M. esculenta against A. fumigatus (A) and $A$. alternata (Bar represents $\pm \mathrm{Sd}$ ). 
Antifungal efficacy of different extracts (mthanolic, ethyl acetate, hot and cold water extracts) of $M$. esculenta against fungal strains namely $T$. citrinoviride, A. fumigatus and A. alternata are presented in Figs 7B, 8A, 8B. Maximum zone of inhibition (66\% ZI) was exhibited by methanol and ethyl acetate extract at $80 \mu \mathrm{l} /$ well of the tested concentration $(1 \mathrm{mg})$. Hot water and ethyl acetate extracts of $1 \mathrm{mg}$ of $M$. esculenta revealed equal ZI (33\%) at both 40 and $60 \mu \mathrm{l} /$ well. The same ZI (33\%) was measured by cold water extract of $1 \mathrm{mg}$ at $40 \mu \mathrm{l} /$ well. At $80 \mu \mathrm{l} /$ well, $1 \mathrm{mg}$ of both hot and cold water extract produced equal ZI of 50\% against $T$. citrinoviride, the same ZI was measured for the cold water extract of at $60 \mu \mathrm{l} /$ well.

Furthermore, ethyl acetate extract of $M$. esculenta did not inhibit the growth of A. fumigatus and A. alternata at any concentration (Figs 8A, 8B). Hot water extracts of $1 \mathrm{mg}$ revealed equal ZI of $66 \%$ at 60 and $80 \mu \mathrm{l} /$ well concentration and the same extract did not inhibit the growth of A.fumigatus at $40 \mu \mathrm{l} /$ well. Methanol extract of $1 \mathrm{mg}$ produced $50 \% \mathrm{ZI}$ at $80 \mu \mathrm{l} /$ well against $A$. fumigatus. However, the same extract did not affect the growth of the same fungus at 40 and 60 $\mu \mathrm{l} /$ well. Cold water extract $(1 \mathrm{mg})$ produced the same zone of inhibition $(50 \% \mathrm{ZI})$ at both 60 and $80 \mu \mathrm{l} /$ well. The same extract produced $33 \% \mathrm{ZI}$ at $40 \mu \mathrm{l} /$ well. Cold water extract was more affective ( $83 \% \mathrm{ZI}$ at $80 \mu \mathrm{l} /$ well) against $A$. alternata as compared to other tested samples. Hot water extract produced $66 \%$ ZI while $50 \%$ ZI was noted for methanolic extract at both 60 and 80 $\mu \mathrm{l} /$ well. Both hot and cold water extracts revealed equal ZI of $66 \%$ at $60 \mu \mathrm{l} /$ well, the same extracts produced 60 and 50\% ZI, respectively at $40 \mu \mathrm{l} /$ well. However Badsha et al. (2012) reported that methanolic, ethanolic and chloroform extracts were ineffective against $A$. fumigatus and A. niger. Furthermore, all the four extracts of the mushroom showed similar activity against $R$. stolonifer during this study. Results also revealed that water extract and methanol extracts were comparatively more affective against fungal species as compared to other extracts. However, cold water extracts is generally more effective than cold extracts for controlling fungal pathogens. Similar findings were also reported by Touba et al. (2011)

Hot water is comparatively best solvent for antibacterial activity and cold water and methanol extract is better for antifungal efficacy. Furthermore $M$. esculenta is more effective against bacteria as compared to fungi.

\section{Acknowledgments}

Authors acknowledge the authorities of the Higher Education Commission (HEC), Islamabad, Pakistan for providing financial support to this study.

\section{References}

Andersson DI and Hughes D 2011. Persistence of antibiotic resistance in bacterial populations. FEMS Microbiol Rev. 35: 901-11.

Baati T, Horcajada P, Gref R, Couvreur P and Serre C 2011. Quantification of fumaric acid in liver, spleen and urine by high-performance liquid chromatography coupled to photodiode-array detection. J. Pharm. Biomed. Anal. 56: 758-762.

Badshah H, Qureshi, RA, Khan J, Ullah F, Fahad S, Ullah F and Khan N 2012. Pharmacological screening of Morchellae sculenta (L.) Pers., Calvatiagigantea (Batsch ex Pers.) Lloyd and Astraeus hygrometricus Pers., mushroom collected from South Waziristan (FATA.). J. Med. Plants Res. 6: 1853-1859.

Halliwell B 2012. Free radicals \& antioxidants: updating a personal view. Nutr. Rev. 70: 257- 265.

Heleno SA, Stojkovic D, Barros L, Glamoclija J, Sokovic M, Martins A, Queiroz MJRP and Ferreira ICFR 2013. A comparative study of chemical composition, antioxidant and antimicrobial properties of Morchella esculenta (L.) Pers. from Portugal and Serbia. Food Res. Int. 51: 236-243. 
Kalyoncu F, Oskay M, Saglam H, Erdogan TF and Tamer AU 2010. Antimicrobial and antioxidant activities of mycelia of 10 wild mushroom species. J. Med. Food. 13: 415-419.

Khan W, Bakht J and Khan BM 2017. In vitro antifungal, anti-oxidant and HPLC analysis of the extracts of Physalis phyladephica. Bangladesh J. Pharmacol. 12: 313-318.

Khan W, Bakht J and Shafi M 2016. Antimicrobial potentials of different solvent extracted samples from Physalis ixocarpa. Pak. J. Pharm. Sci. 29: 467-475.

Khan W, Bakht, J, Nair MG, Uddin MN and Shafi M. 2018. Extraction and isolation of important bioactive compounds from the fruit of Physalis ixocarpa." Pak. J. Pharm. Sci. 31: 2463-2469.

Lowy F 2003. Antimicrobial resistance: the example of Staphylococcus aureus. J. Clin. Invest. 111: 1265-73.

Mahmood A, Malik RN, Shinwari ZK and Mahmood A 2011. Ethnobotanical survey of plants from Neelum, Azad Jammu \& Kashmir, Pakistan. Pak. J. Bot. 43: 105-110.

Srivastava J, Chandra H, Nautiyal AR and Kalra SJS 2013. Antimicrobial resistance (AMR) and plantderived antimicrobials (PDAms) as an alternative drug line to control infections. Biotech. 4: 451-60.

Touba EP1, Zakaria M and Tahereh E 2011.Anti-fungal activity of cold and hot water extracts of spices against fungal pathogens of roselle (Hibiscus sabdariffa) in vitro. Microb. Pathog. 52:125-9.

Walsh T and Toleman M. 2012. The emergence of pan-resistant Gram-negative pathogens merits a rapid global political response. J. Antimicrob Chemother. 67: 1-3.

(Manuscript received on 25 July, 2018; revised on 25 December, 2018) 